\title{
Dystonia associated with carbamazepine toxicity
}

\author{
A. J. BRADBURY \\ D.C.H., M.R.C.P. \\ B. BENTICK \\ M.B., D.R.C.O.G. \\ P. J. TODD* \\ D.C.H., M.R.C.P.
}

Department of Child Health, Alder Hey Children's Hospital, Eaton Road, Liverpool L12 2AP, and *Royal Liverpool Children's Hospital, Myrtle Street, Liverpool L7 7DG

\section{Summary}

An uncommonly reported toxic effect of carbamazepine is a dystonic reaction. We report two children who developed dystonic reactions with toxic serum levels of carbamazepine.

\section{Case reports}

Case 1

An 11-year-old boy presented with a 1-year history of attacks of unconsciousness lasting about $10 \mathrm{~min}$. There were no tonic or clonic movements. Some attacks were photically induced. An electroencephalogram was abnormal with excessive slow wave activity over the left cerebral hemisphere. He was treated with carbamazepine $(5.7 \mathrm{mg} / \mathrm{kg})$ twice daily. One month later he presented with an 8-hr history of diplopia, dizziness, fainting and stiffening of his limbs. His level of consciousness was fluctuating and he was having severe dystonic movements which were exacerbated by disturbance. There was opisthotonic posturing with extension of the limbs but flexion of the wrists. Shortly after admission he had a grand mal fit which was terminated after 5 min by intravenous diazepam. His serum carbamazepine level was $21 \mu \mathrm{g} / \mathrm{ml}$ on admission (therapeutic range 4-8 $\mu \mathrm{g} / \mathrm{ml}$ ). He subsequently admitted to taking double his usual dose for the 2 days before admission. He recovered spontaneously over a 12-hr period, the dystonia lasting approximately $6 \mathrm{hr}$. His previous dose of carbamazepine was continued and his most recent serum level was $9 \cdot 3 \mu \mathrm{g} / \mathrm{ml}$.

\section{Case 2}

An 11-year-old girl presented following a number

Correspondence: Dr A. J. Bradbury, Department of Child Health, Alder Hey Children's Hospital, Eaton Road, Liverpool L12 2AP of episodes of unconsciousness lasting several minutes. There was a family history of epilepsy. An electroencephalogram was abnormal with paroxysmal sharp and slow wave activity more marked over the right cerebral hemisphere. She was treated with carbamazepine $(5 \mathrm{mg} / \mathrm{kg})$ twice daily. She presented a year later following 2 convulsions. On admission she was unconscious and hypotonic and on disturbance was noted to have intermittent extension of all her limbs. At times minor disturbance induced very severe dystonic movements of the limbs with extension of the trunk and neck. Investigations including blood electrolytes were normal except for a carbamazepine level on admission of $25 \mu \mathrm{g} / \mathrm{ml}$. She received a diazepam infusion and her symptoms resolved in 24 $\mathrm{hr}$, the dystonia having been present for $17 \mathrm{hr}$. There was no history of excessive medication or of ingestion of other drugs. Her dose of carbamazepine was reduced to $3.75 \mathrm{mg} / \mathrm{kg}$ twice daily and the most recent blood level was $5 \mu \mathrm{g} / \mathrm{ml}$.

\section{Discussion}

Carbamazepine is widely used in the treatment of epilepsy and has also been used in the treatment of dystonia. Reported side effects include ataxia, dizziness, drowsiness, diplopia, dry mouth, nausea, vomiting, diarrhoea, rashes, blood dyscrasias and abnormal liver function with prolonged treatment (Wade, 1977). Hyponatremia has been reported in a few patients and acute overdose may lead to convulsions (Bailey, 1981). Dystonic reactions rarely have been reported. Crosley and Swender (1979) reported 3 cases of dystonia associated with carbamazepine administration in brain-damaged children. Their patients had received other drugs in addition to carbamazepine. Jacome (1979) reported 4 cases of dystonia associated with carbamazepine in adults on treatment for epilepsy. In 3 cases the carbamazepine 
was an addition to therapy and in the fourth the dose had recently been doubled. Lehrman and Bauman (1981) reported a case of deliberate carbamazepine poisoning in which opisthotonic posturing and abnormal movements were noted. These symptoms were controlled with physostigmine.

In both of our patients the dystonia was clearly associated with toxic serum levels of carbamazepine. In the first case the boy had taken an excessive amount of carbamazepine. In the second case it is not clear how the toxic level was achieved. The carbama-4 zepine dosage was only $10 \mathrm{mg} / \mathrm{kg} /$ day and thus acute overdosage remains a possibility. In neither case was there a history of abuse of other drugs although it would have been interesting to take blood and urine from the patients on admission for toxicology screening. The dystonia appears to have been the result of toxic levels of carbamazepine since it rapidly disap- peared after drug withdrawal and has not recurred in association with the current lower serum levels.

\section{Acknowledgments}

We wish to thank Professor F. Harris and Dr J. Rees Roberts for permission to publish their cases, Mr A. J. Nunn for performing aㄷ literature search and Mrs P. Moore for typing the manuscript.

\section{References}

Bailey, A.J.M. (1981) Data Sheet Compendium 1981-82. p. 408. Datapharm Publications, London.

Crosley, C.J. \& SWENDER, P.T. (1979) Dystonia associated with $\overrightarrow{0}$ carbamazepine administration: experience in brain-damagedchildren. Pediatrics, 63, 612.

JACOME, D. (1979) Carbamazepine-induced dystonia. Journal of the American Medical Association, 241, 2263.

LEHRMAN, S.N. \& BAUMAN, M.L. (1981) Carbamazepine overdose. American Journal of Diseases of Children, 135, 768.

WADE, A. (Ed.) (1977) Martindale, The Extra Pharmacopoeia, 27th edn, p. 1236. The Pharmaceutical Press, London. 